\title{
Two instruments based on differential optical absorption spectroscopy (DOAS) to measure accurate ammonia concentrations in the atmosphere
}

\author{
H. Volten ${ }^{1}$, J. B. Bergwerff ${ }^{1}$, M. Haaima ${ }^{1}$, D. E. Lolkema ${ }^{1}$, A. J. C. Berkhout ${ }^{1}$, G. R. van $\operatorname{der}_{\text {Hoff }}{ }^{1}$, C. J. M. Potma ${ }^{1}$, \\ R. J. Wichink Kruit ${ }^{1,2, *}$, W. A. J. van Pul ${ }^{1}$, and D. P. J. Swart ${ }^{1}$ \\ ${ }^{1}$ Centre for Environmental Monitoring, Netherlands National Institute for Public Health and the Environment (RIVM), \\ P.O. Box 1, 3720 BA Bilthoven, The Netherlands \\ ${ }^{2}$ Department of Meteorology and Air Quality, Wageningen University, Research Centre (WUR), Postbus 47, \\ 6700 AA Wageningen, The Netherlands \\ *now at: TNO, Department of Climate, Air and Sustainability, P.O. Box 80015, 3508 TA Utrecht, The Netherlands
}

Correspondence to: H. Volten (hester.volten@rivm.nl)

Received: 11 April 2011 - Published in Atmos. Meas. Tech. Discuss.: 9 August 2011

Revised: 24 November 2011 - Accepted: 13 January 2012 - Published: 21 February 2012

\begin{abstract}
We present two Differential Optical Absorption Spectroscopy (DOAS) instruments built at RIVM: the RIVM DOAS and the miniDOAS. Both instruments provide virtually interference-free measurements of $\mathrm{NH}_{3}$ concentrations in the atmosphere, since they measure over an open path, without suffering from inlet problems or interference problems by ammonium aerosols dissociating on tubes or filters. They measure concentrations up to at least $200 \mu \mathrm{g} \mathrm{m}^{-3}$, have a fast response, low maintenance demands, and a high uptime. The RIVM DOAS has a high accuracy of typically $0.15 \mu \mathrm{g} \mathrm{m}^{-3}$ for ammonia for 5-min averages and over a total light path of $100 \mathrm{~m}$. The miniDOAS has been developed for application in measurement networks such as the Dutch National Air Quality Monitoring Network (LML). Compared to the RIVM DOAS it has a similar accuracy, but is significantly reduced in size, costs, and handling complexity. The RIVM DOAS and miniDOAS results showed excellent agreement $\left(R^{2}=0.996\right)$ during a field measurement campaign in Vredepeel, the Netherlands. This measurement site is located in an agricultural area and is characterized by highly variable, but on average high ammonia concentrations in the air. The RIVM-DOAS and miniDOAS results were compared to the results of the AMOR instrument, a continuous-flow wet denuder system, which is currently used in the LML. Averaged over longer time spans of typically a day, the (mini)DOAS and AMOR results agree reasonably well, although an off-
\end{abstract}

set of the AMOR values compared to the (mini)DOAS results exists. On short time scales, the (mini)DOAS shows a faster response and does not show the memory effects due to inlet tubing and transport of absorption fluids encountered by the AMOR. Due to its high accuracy, high uptime, low maintenance and its open path, the (mini)DOAS shows a good potential for flux measurements by using two (or more) systems in a gradient set-up and applying the aerodynamic gradient technique.

\section{Introduction}

Excessive deposition of ammonia leads to acidification and eutrophication, which form important threats to biodiversity of nature areas. In addition, ammonia plays an important role in the formation of aerosols (Asman et al., 1998). Since different ammonia sources (differing by type or by geolocation) have different influence on the acidification and eutrophication processes, it is of great importance to have a correct understanding of the processes that determine ammonia emissions. Understanding these processes starts with a good inventory of concentrations and deposition fluxes of ammonia.

There are several techniques to measure atmospheric ammonia concentrations. Two commonly used and well-known techniques are passive samplers (see e.g. Thijsse et al., 1998)

Published by Copernicus Publications on behalf of the European Geosciences Union. 
and annular denuder systems (see e.g. Wyers et al., 1993; Van Putten et al., 1994). Such annular denuder systems are used in the Dutch National Air Quality Monitoring Network (LML) to monitor ammonia concentrations throughout the Netherlands. They are extremely costly in maintenance, i.e. $15000 €$ per instrument per annum. Denuders were also used in a gradient set-up to obtain ammonia fluxes by means of the aerodynamic gradient technique (Wichink Kruit et al., 2007). Other methods to measure ammonia concentrations include wet chemistry analyzers, quantum cascade laser absorption spectroscopy, photoacoustic spectroscopy, and cavity ring down spectroscopy. Most techniques are sampling techniques and therefore involve direct contact with the highly adhesive ammonia resulting in inlet problems, e.g. causing slow response times and problems with interference by ammonium aerosols dissociating on tubes or filters (e.g. von Bobrutzki et al., 2010). This is a severe disadvantage for process studies. Therefore, a new system has been developed based on the open path differential optical absorption spectroscopy (DOAS) technique. The DOAS technique has been applied previously to measure atmospheric ammonia concentrations by Edner et al. (1990, 1993) and Mount et al. (2002), and commercially by OPSIS (http://opsis.se).

The RIVM DOAS system described in this paper has been developed by the National Institute for Public Health and the Environment (RIVM) to measure ammonia concentrations with a fast time response. The system has a high accuracy (typically $0.15 \mu \mathrm{g} \mathrm{m}^{-3}$ for ammonia for 5 -min averages over a total light path of $100 \mathrm{~m}$ ), low maintenance demands and a high up-time. Together with its fast time response, this makes the system suitable for process studies and for other applications such as deposition measurements. However, its complexity in handling, bulkiness, and building costs render it less suitable for the use in most monitoring networks. Therefore, a simplified second instrument, the miniDOAS, was developed. The instrument has specifications similar to the RIVM DOAS, but is significantly reduced in size, costs, and handling complexity. The miniDOAS instrument is highly suitable to be introduced in a measurement network such as the LML.

The DOAS measurement principle is explained in Sect. 2. Section 3 describes the instrumental designs of the RIVM DOAS instrument and the miniDOAS. A detailed description of how concentration values are derived from the analysis of the measured optical absorption spectra is given in Sect. 4. This analysis is the same for both instruments. In Sect. 5 we present the results of laboratory tests for the RIVM DOAS instrument, which we consider as the reference instrument. We investigated the linearity of its response to $\mathrm{NH}_{3}$ and the potential interference from $\mathrm{NO}$ and $\mathrm{SO}_{2}$. Section 6 describes the results of a field comparison campaign conducted at an LML measurement site with highly variable, but on average high ammonia concentrations. The results of the RIVM DOAS and miniDOAS were compared. In addition, we compared the (mini)DOAS results with the results of the currently used LML instrument, an annular denuder system, AMOR (Wyers et al., 1993). We end with conclusions and an outlook in Sect. 7.

\section{Measurement method}

The DOAS technique is based on the wavelength dependent absorption of light over a specified light path. The total extinction (= absorption + scattering) is expressed by LambertBeer's law

$I_{\lambda}=I_{0, \lambda} \cdot \exp \left[-\left(\alpha_{i, \lambda} \cdot C_{i}+\epsilon_{\mathrm{M}}+\epsilon_{\mathrm{R}}\right) \cdot L\right]$

with $I_{\lambda}$ the received light intensity at wavelength $\lambda, I_{0, \lambda}$ the emitted light intensity at wavelength $\lambda, \alpha_{i, \lambda}$ the absorption coefficient for trace gas $i$ at wavelength $\lambda, C_{i}$ the concentration of trace gas $i, \epsilon_{\mathrm{M}}$ the extinction by small particle (Mie) scattering per unit of length, $\epsilon_{\mathrm{R}}$ the extinction by Rayleigh scattering per unit of length, and $L$ the length of the light path. The total extinction comprises broadband extinction (Rayleigh and Mie scattering and broadband absorption) and narrowband extinction (narrowband absorption). In the wavelength range used, from $200 \mathrm{~nm}$ to $230 \mathrm{~nm}$, the broadband extinction is dominated by Rayleigh scattering and ozone absorption, and can be described by a smooth polynomial function. After extracting the broadband extinction from an observed spectrum, a narrowband absorption spectrum is left with absorption lines of a limited number of gas species. A detailed description of how the concentrations are determined from these narrowband absorption spectra is given in Sect. 4.

\section{Wavelength selection}

The DOAS technique is often applied in the UV and visible parts of the electromagnetic spectrum. The absorption lines and bands of gas molecules in this part of the spectrum are caused by electronic transitions and their shapes only weakly depend on atmospheric temperature and pressure. Ammonia has a strong absorption band with narrowband features in the UV part of the spectrum from about 170 to $220 \mathrm{~nm}$ (Chen et al., 1999). Ammonia also has lines in the IR part of the spectrum, but in this region strong water bands may interfere with the ammonia lines. Absorption by atmospheric trace gases cannot be measured below $204 \mathrm{~nm}$ because of the strong absorption by oxygen; i.e. the atmosphere is not transparent below $204 \mathrm{~nm}$. In the wavelength range $204-230 \mathrm{~nm}$, there is narrowband absorption only by ammonia $\left(\mathrm{NH}_{3}\right)$, nitrogen monoxide $(\mathrm{NO})$, and sulfur dioxide $\left(\mathrm{SO}_{2}\right)$. Other absorbers are oxygen $\left(\mathrm{O}_{2}\right)$, ozone $\left(\mathrm{O}_{3}\right)$, carbon dioxide $\left(\mathrm{CO}_{2}\right)$, nitrogen dioxide $\left(\mathrm{NO}_{2}\right)$, and nitrous oxide $\left(\mathrm{N}_{2} \mathrm{O}\right)$. Figure 1 shows the absorption cross sections of all these gases for the wavelength range $200-230 \mathrm{~nm}$. Data is taken from the "MPI-Mainz-UV-VIS Spectral Atlas of Gaseous Molecules" 


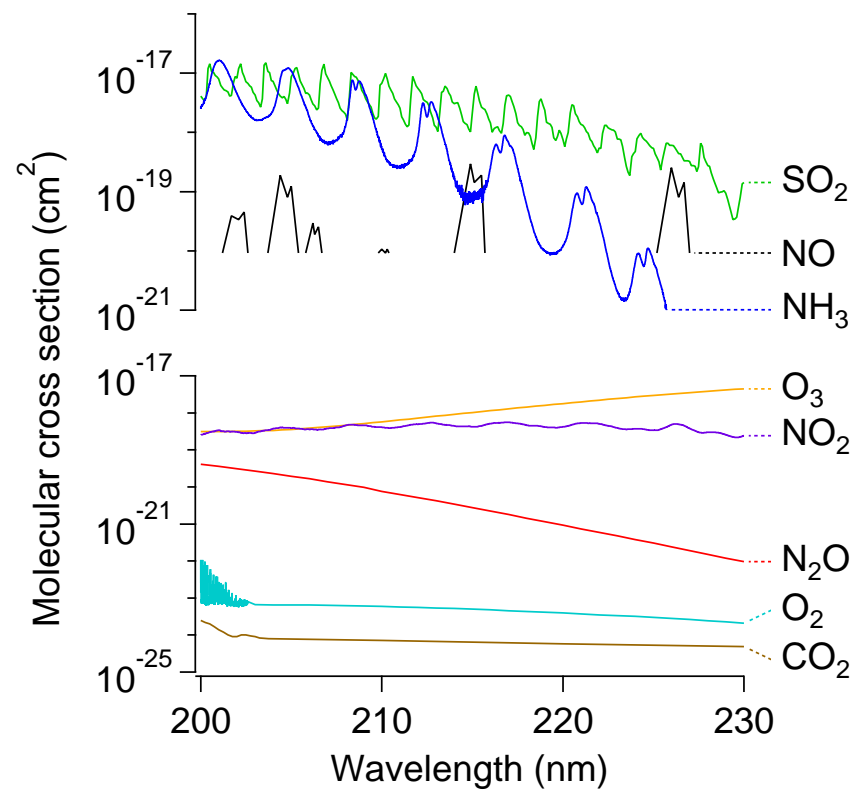

Fig. 1. Upper graph: absorption by $\mathrm{NH}_{3}(T=295 \mathrm{~K}$; Chen et al., 1999), NO ( $T=298 \mathrm{~K}$; spectrum only partly available; Thompson et al., 1963), and $\mathrm{SO}_{2}(T=293 \mathrm{~K}$; Manatt and Lane, 1993). Lower graph: $\mathrm{CO}_{2}\left(T=298 \mathrm{~K}\right.$; Shemansky, 1972), $\mathrm{NO}_{2}(T=293 \mathrm{~K}$; Jenouvrier et al., 1996), $\mathrm{O}_{3}(T=298 \mathrm{~K}$; Molina and Molina, 1986), $\mathrm{O}_{2}$ Schumann-Runge bands ( $T=300 \mathrm{~K}$; Yoshino et al., 1992), and $\mathrm{O}_{2}$ Herzberg continuum ( $T=298 \mathrm{~K}$; Cheung et al., 1986), and $\mathrm{N}_{2} \mathrm{O}$ ( $T=301 \mathrm{~K}$; Selwyn et al., 1977).

(Keller-Rudek and Moortgat, 2010). The NO spectrum is only partly available in this wavelength range. From Fig. 1 it is clear that in the wavelength range $204-230 \mathrm{~nm}$ there is only narrowband absorption by ammonia, nitrogen monoxide, sulfur dioxide and nitrogen dioxide. Therefore, a DOAS analysis to measure ammonia in this wavelength range must also include $\mathrm{NO}$ and $\mathrm{SO}_{2}$. The features from nitrogen dioxide $\left(\mathrm{NO}_{2}\right)$ are weak at typical ambient concentrations of around $20 \mathrm{ppb}$ and not taken into account.

\section{Instrument design}

\subsection{The RIVM DOAS instrument}

The RIVM DOAS is designed to measure atmospheric ammonia concentrations with high accuracy. Figures 2 and 3 show a schematic overview and a photograph of the instrument, respectively. The instrument uses a combined sender/receiver unit (Thermo, DOAS 2000), consisting of a $150 \mathrm{~W}$ xenon lamp (Hamamatsu, L2273) placed in the focal point (at $46 \mathrm{~cm}$ ) of a $23 \mathrm{~cm}$ diameter Cassegrain telescope. A corner cube retroreflector directs the lamplight directly back to the telescope. The outer ring of the primary mirror of the telescope is used to send the light, the inner part of the mirror is the receiver. The retroreflector is placed at approximately
$50 \mathrm{~m}$ from the sender/receiver unit. This results in an effective light path of approximately $100 \mathrm{~m}$. The retroreflector is heated slightly to prevent dew formation. Moisture on the retroreflector would diminish the light gain and disturb the measurements.

The light received by the telescope is focused by the secondary mirror and a folding mirror onto an optical fiber bundle with an narrowband-pass interference filter (Newport, G25-206-F, center wavelength $206 \mathrm{~nm}$, bandwidth $26 \mathrm{~nm}$ FWHM) placed in front of it. This interference filter is necessary to overcome problems caused by stray light in the spectrograph. Its center wavelength is optimal for the region of 200 to $215 \mathrm{~nm}$, where the strongest and most distinctive spectral features of ammonia are located, but where the intensity of the xenon lamp is lowest. At $200 \mathrm{~nm}$ the intensity of the UV lamp is only about one hundredth of the intensity at $400 \mathrm{~nm}$ and beyond. Thus, even small amounts of visible light straying off course in the spectrograph and reaching the detector will cause signal levels comparable to those of the light from our wavelength region of interest. Peak transmittance for this filter type is at least $20 \%$. The optical fiber bundle is a spot/spot to slit line bundle assembly (see Fig. 4) that leads the light of the telescope to the slit of a spectrograph (Jobin Yvon, TRIAX 320, grating 2400 lines $/ \mathrm{mm}$, blaze $330 \mathrm{~nm}$ ). Light in the wavelength-range $200-230 \mathrm{~nm}$ is projected onto a charge-coupled device (CCD) detector (Jobin Yvon, SpectrumOne/Symphony, $256 \times 1024$ pixels, $16 \mathrm{bit})$. The resulting wavelength mapping is $0.0306 \mathrm{~nm}$ per pixel. The CCD detector is thermo-electrically cooled to suppress dark current. This combination of spectrograph and CCD detector ensures a high accuracy even at low levels of light intensity. Data is usually averaged for $5 \mathrm{~min}$ to increase the signal-to-noise ratio. All system control and data storage is managed by a computer.

The correct mapping of the different wavelengths onto the CCD is crucial to the accuracy of the overall measurement. This mapping, however, changes in time due to temperature variations in the CCD and spectrograph (see Fig. 5). To prevent this drift a zinc lamp is used to track the wavelengths. The zinc lamp has a distinctive emission line at $213.84 \mathrm{~nm}$ with a narrow linewidth of $0.10 \mathrm{~nm}$. Its light is projected onto the spectrograph, along with the light from the telescope. The peak position of the zinc emission line on the CCD pixels is determined at sub-pixel resolution with a quadratic polynomial fit. This position is checked every minute. If the position deviates by more than $0.0012 \mathrm{~nm}$ from the desired position, the grating angle is micro-adjusted by a stepper motor with a resolution of $0.0010 \mathrm{~nm}$. As a result, the wavelength mapping is locked onto the CCD with an accuracy of $0.0025 \mathrm{~nm}$ (see Fig. 5).

The sender/receiver unit is equipped with stepper motors to move its pointing direction. These are used to keep the alignment between the sender/receiver unit and the retroreflector optimal. Every $30 \mathrm{~min}$, an automated alignment procedure is executed in which the pointing direction is scanned 


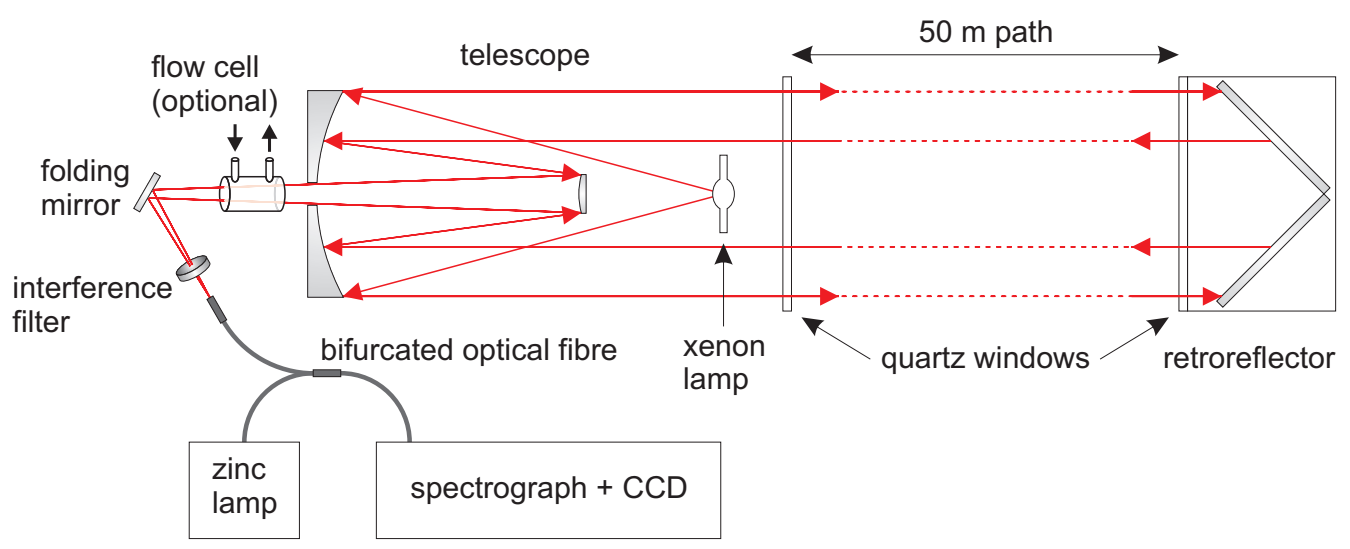

Fig. 2. Schematic overview of the RIVM DOAS design. The light of a xenon lamp is directed by the combined sender/receiver telescope to a corner cube retroreflector, placed at a distance of $50 \mathrm{~m}$. The light is reflected back to the telescope by the retroreflector. With the use of two mirrors the light is focussed onto an optical fiber that couples the light into the spectrograph followed by a CCD detector, after passing through an interference filter. The zinc lamp with its distinctive emission peak around $213.9 \mathrm{~nm}$ is used for calibrating the wavelength mapping onto the CCD. The optional flow cell is used to supply known amounts of traces gases for calibration measurements.

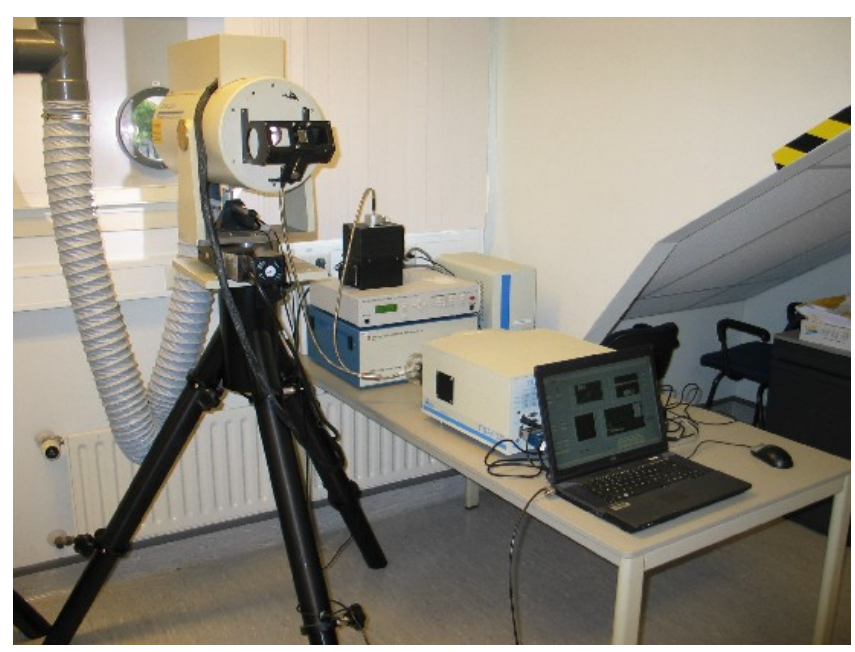

Fig. 3. Photograph of the RIVM DOAS instrument.

through a $5 \times 5$ grid of positions around the current direction, in steps of $0.0075^{\circ}$. For each direction, the intensity of the reflected light is determined. The direction with the highest intensity is chosen as the current direction for the next $30 \mathrm{~min}$ measuring period. Although the accuracy of the concentration measurement during the alignment procedure is smaller, it is still good enough for data analysis, so no measurement time is lost.

\subsection{The RIVM MiniDOAS instrument}

The miniDOAS is designed to be smaller and less expensive than the RIVM DOAS instrument, so that it may conveniently be used in an environmental monitoring network. The main differences in design are that the sender and re-
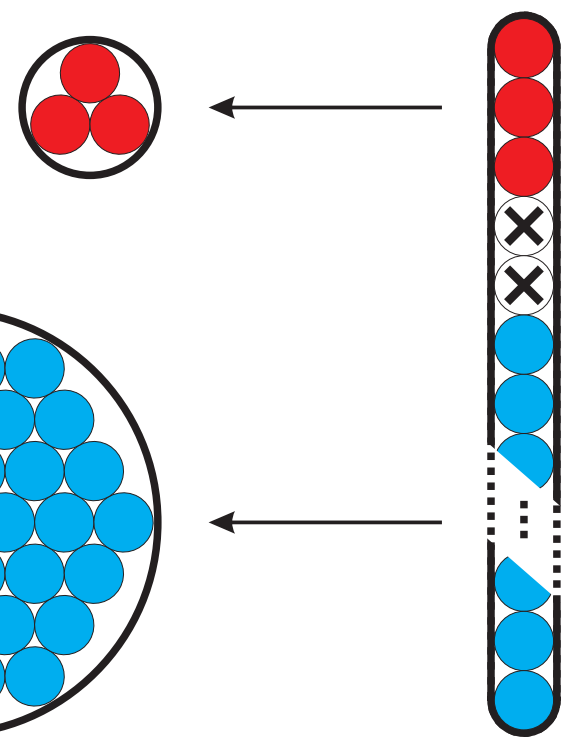

Fig. 4. The optical fiber bundle is a spot/spot to slit line bundle assembly. The end going to the spectrograph consists of 47 fibers formatted into a slit line. The other end of the bundle is divided into two legs. One leg contains the top 3 fibers from the slit line formatted into a spot. This end leads to the zinc lamp. The next 2 fibers from the slit line are intentionally dark (dead). The other leg consists of the remaining 42 fibers formatted into a spot. The light of the telescope is focussed on this spot.

ceiver are no longer combined, and that the optical fiber, which has a transmittance of only a few percent in the UV, has been eliminated. The spectrograph with integrated CCD detector (Avantes AvaSpec-2048x14) used in the miniDOAS set-up is small in size, $175 \mathrm{~mm} \times 110 \mathrm{~mm} \times 44 \mathrm{~mm}$; it can directly be aligned in the optical train (see Figs. 6 and 7). 


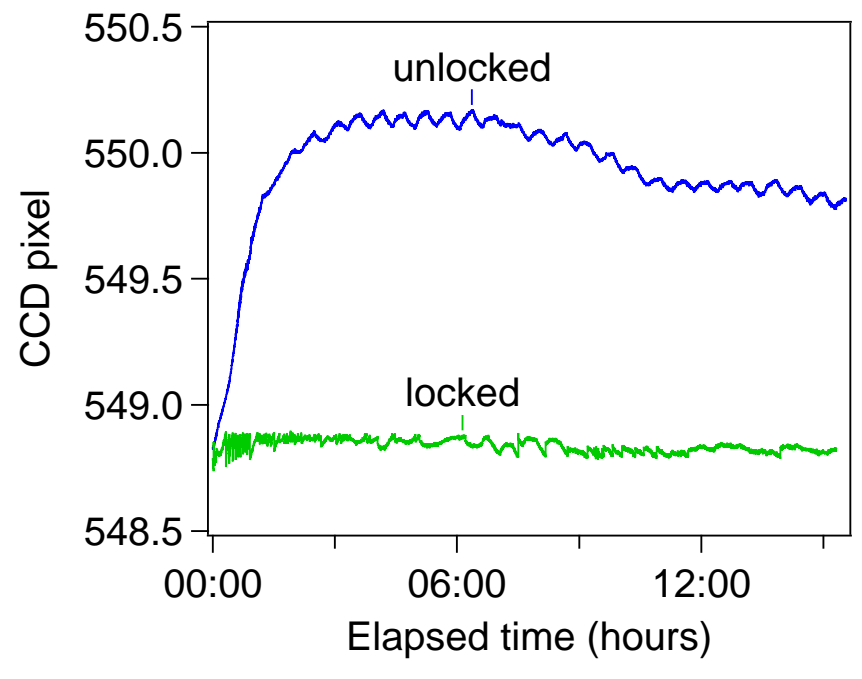

Fig. 5. Peak position in pixels on the CCD detector of the zinc peak as function of time. The upper line shows the zinc peak position in unlocked mode. The lower line shows the zinc peak position in locked mode. A drift in wavelength mapping of one pixel (corresponding to $0.0306 \mathrm{~nm}$ ) is easily reached in unlocked mode.

The parabolic sender mirror is smaller ( $152.4 \mathrm{~mm}$ diameter) than the one used in the large RIVM DOAS. The mirror is $75.4 \mathrm{~mm}$ deep, its focal length is $19.1 \mathrm{~mm}$, which implies that the focal point lies well within the mirror. The light of the $150 \mathrm{~W}$ xenon lamp (Hamamatsu, L2273) placed in the focal point is thus more efficiently used. At $200 \mathrm{~nm}$, where the reflectivity of the enhanced aluminium mirror coating is about $60 \%$, around $40 \%$ of the total amount of light emitted by the lamp is sent towards the retroreflector. For the RIVM DOAS this value is only about $1.5 \%$.

Subsequently, we make use of the fact that the corner cube retroreflector reflects the light directly to the sender telescope, but with a slight displacement. The displacement ensures that some of the reflected light falls onto the receiver parabolic mirror. Thus only a small fraction of the light reflected by the retroreflector is used. We can afford this lack of efficiency, since the intensity losses in the miniDOAS are two to three orders of magnitudes less than in the RIVM DOAS due to a more efficient use of the lamp ( $40 \%$ versus $1.5 \%$ ) and the elimination of the optical fiber (efficiency in the UV of only a few percent).

The received light is focussed onto the spectrograph after passing a folding mirror and the interference filter. The spectrograph has a grating of 2400 lines $/ \mathrm{mm}$. The wavelength resolution is therefore less than for the RIVM DOAS. Light in the wavelength range $200-315 \mathrm{~nm}$ is projected onto an integrated back-thinned charge CCD image sensor with $2048 \times 14$ pixels (16 bit). The resulting wavelength mapping is $0.056 \mathrm{~nm}$ per pixel. Because we use only the wavelength range from $200 \mathrm{~nm}$ to $230 \mathrm{~nm}$, about $534 \times 14$ pixels are actually utilized. The lower resolution and sensitivity of this combination of spectrograph and CCD sensor is compensated by the higher light intensity levels obtained in the RIVM miniDOAS compared to the RIVM DOAS.

Since for the miniDOAS no optical fiber is applied, we cannot use a zinc lamp to correct for the potential drift in the wavelength mapping onto the CCD. For this reason two extra steps are added in the analysis of the measured results. First, in the fitting procedure (see Sect. 2) the spectrum is allowed to shift until a minimum in $\sigma$ is reached (see Eq. 3). Second, the signal is corrected for a fixed pattern in the CCD response.

An automated alignment procedure as used for the large RIVM DOAS is unnecessary for the miniDOAS, because the spot of light coming from the sender mirror is slightly diverging and thus produces a roughly ten times larger spot falling on the retroreflector, than for the sender of the RIVM DOAS that produces a nearly perfectly parallel beam projecting a spot with a diameter of $10-15 \mathrm{~cm}$ onto the retroreflector. The miniDOAS is therefore not very sensitive to small changes in the alignment of the lamp and sender mirror. In addition, the spot of light falling on the entrance slit (with a width of $100 \mu \mathrm{m}$ ) is relatively large (about $5 \times 2 \mathrm{~mm}$ ) compared to the spot imaged on the optical fiber bundle of the RIVM DOAS $(<1 \mathrm{~mm}$, with the fiber bundle diameter being $0.13 \mathrm{~mm}$ ).

The miniDOAS instrument, excluding the retroreflector, fits on a $75 \mathrm{~cm}$ by $50 \mathrm{~cm}$ breadboard (Fig. 7). Its total dimensions are comparable to that of just the spectrograph of the large RIVM DOAS.

\section{Analysis of the optical absorption spectra}

The DOAS technique is based on the wavelength dependent absorption of light over a specified light path, with the total extinction expressed by Lambert-Beer's law (Eq. 1). We rearrange the elements in Lambert-Beer's law to separate the broadband extinction from the narrowband extinction

$\frac{\ln \left(I_{0, \lambda} / I_{\lambda}\right)}{L}=\left(\alpha_{i, \lambda} \cdot C_{i}\right)+\left(\alpha_{i, \lambda}^{\prime} \cdot C_{i}^{\prime}+\epsilon_{\mathrm{M}}+\epsilon_{\mathrm{R}}\right)$

with $\alpha_{i, \lambda}$ and $C_{i}$ denoting the absorption coefficient for and concentration of those species with narrowband absorption, and $\alpha_{i, \lambda}^{\prime}$ and $C_{i}^{\prime}$ denoting the absorption coefficient for and concentration of those species with broadband absorption. The total broadband absorption $\left(\alpha_{i, \lambda}^{\prime} \cdot C_{i}^{\prime}+\epsilon_{\mathrm{M}}+\epsilon_{\mathrm{R}}\right)$ can be estimated by either a polynomial or a moving (boxcar) average. For our analysis a moving average over 75 channels gives the best results. What remains is the extinction by narrowband absorption.

To solve the remainder of Eq. (2), i.e. the narrowband absorption, we need to know the emitted light intensity and the absorption spectra of the species of interest. The emitted light intensity as a function of wavelength $\left(I_{o, \lambda}\right)$ is different for each individual lamp and will change during its life span. For each lamp, the emitted spectrum, unaffected by absorption from gases in the atmosphere, is measured once, using a 


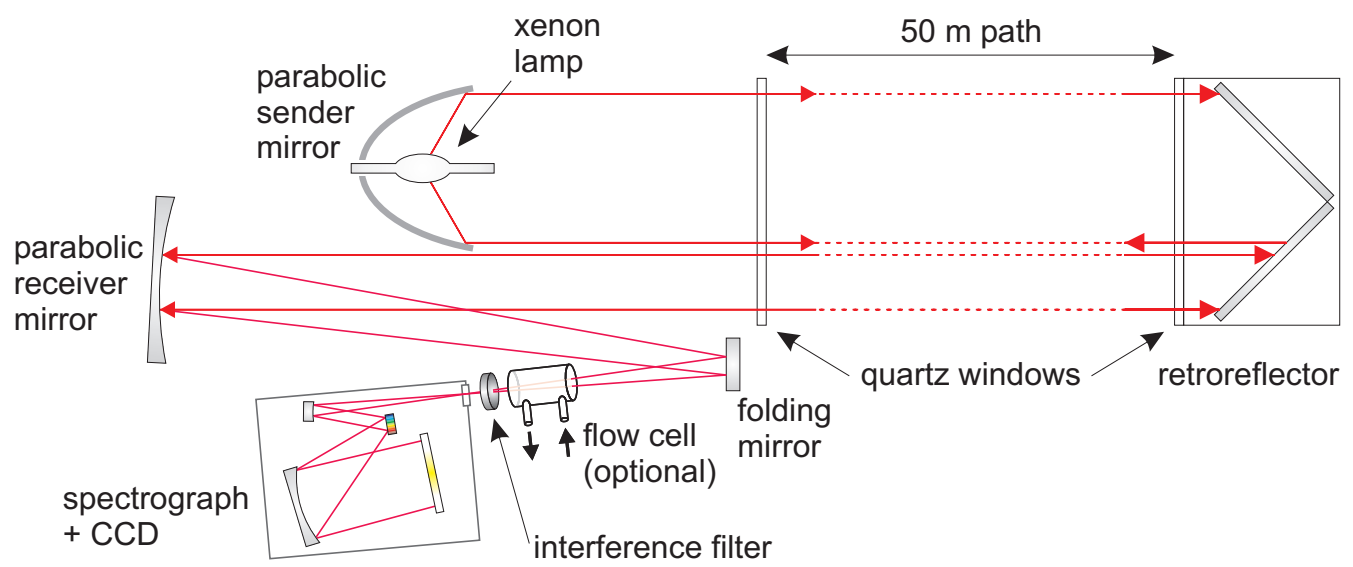

Fig. 6. Schematic overview of the miniDOAS design. The light of a xenon lamp is directed by the parabolic mirror to a corner cube retroreflector, placed at a distance of $50 \mathrm{~m}$. The light is reflected back to the receiving mirror by the retroreflector. With the use of a folding mirror the light is focussed onto an spectrograph with an integrated CCD detector, after passing through an interference filter. The flow cell is optional and is used to supply known amounts of trace gases for calibration measurements.

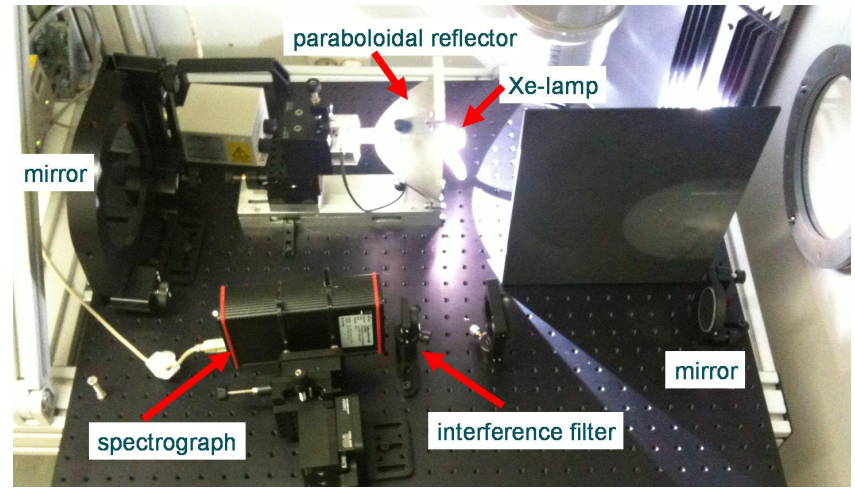

Fig. 7. Photograph of the miniDOAS breadboard instrument.

short light path of $1 \mathrm{~m}$, by placing the retroreflector at a distance of $50 \mathrm{~cm}$. Since for real concentration measurements the retroreflector is placed at a distance of $50 \mathrm{~m}$, any gas that is present in the atmosphere will induce an error of $1 \%$ of its concentration during the lamp spectrum measurements. As those measurements are performed in a well ventilated room and ambient concentrations are expected to be low, we assume that this value may be neglected. The potential spectral changes during a lamp life span are broadband changes and are accounted for in the moving average that is used to estimate the broadband extinction. The reference spectra are absorption spectra of the species of interest (i.e. ammonia, nitrogen monoxide and sulfur dioxide); they are measured by supplying a known amount of trace gas in a flow cell (see Figs. 2 and 6) placed in a short light path of about $1 \mathrm{~m}$ (see Sect. 5). In addition, a measurement is performed with an empty cell placed in the light path. This measurement is used to correct for optical effects of the cell on the absorption spectra. These measurements are performed for each DOAS system individually, thereby accounting for specific instrument features. For a measurement of a background spectrum, we use BK7-glass (plain window glass) which is transparent in the visual range down to $350 \mathrm{~nm}$, but blocks all light in the UV range. The background spectrum is subtracted from all measured spectra. Finally, a three component least squares fit (Kendall and Stuart, 1967) over the wavelength range 205 to $229 \mathrm{~nm}$ is performed to determine the concentrations of ammonia, nitrogen monoxide and sulfur dioxide, using Eq. (3)

$\sigma^{2}=\sum_{j_{0}}^{j}\left(M_{j}-\alpha \times X_{j}-\beta \times Y_{j}-\gamma \times Z_{j}\right)^{2} /(n-3)$

in which $\sigma$ is the standard deviation of the fit. The wavelength at which a measurement was performed is denoted by $j, M$ is the measured spectrum, $n$ is the total number of measurements, and $X, Y, Z$ are the reference spectra for $\mathrm{NH}_{3}$, $\mathrm{NO}$, and $\mathrm{SO}_{2}$, respectively. The parameters $\alpha, \beta$ and $\gamma$ are proportional to the concentrations to be derived. The best fit is obtained by minimizing $\sigma^{2}$.

We found experimentally that narrowing the wavelength range to 205-229 nm was optimal for avoiding edge effects caused by the moving averaging, and for eliminating parts of the spectrum that either are noisy (at the shorter wavelengths, due to Rayleigh extinction and the onset of oxygen absorption) or do not contain absorption features (at the longer wavelengths). An example of the different stages in the analysis is shown in Fig. 8. The residual spectrum, similar to $\sigma$, indicates the goodness of the fit. In addition, it is a tool that helps to identify potential flaws in the measurements, such as interference problems.

\section{Uncertainties in the measurements}

After the fitting procedure a residual spectrum remains. This residual is mainly due to photon noise and detector noise. 

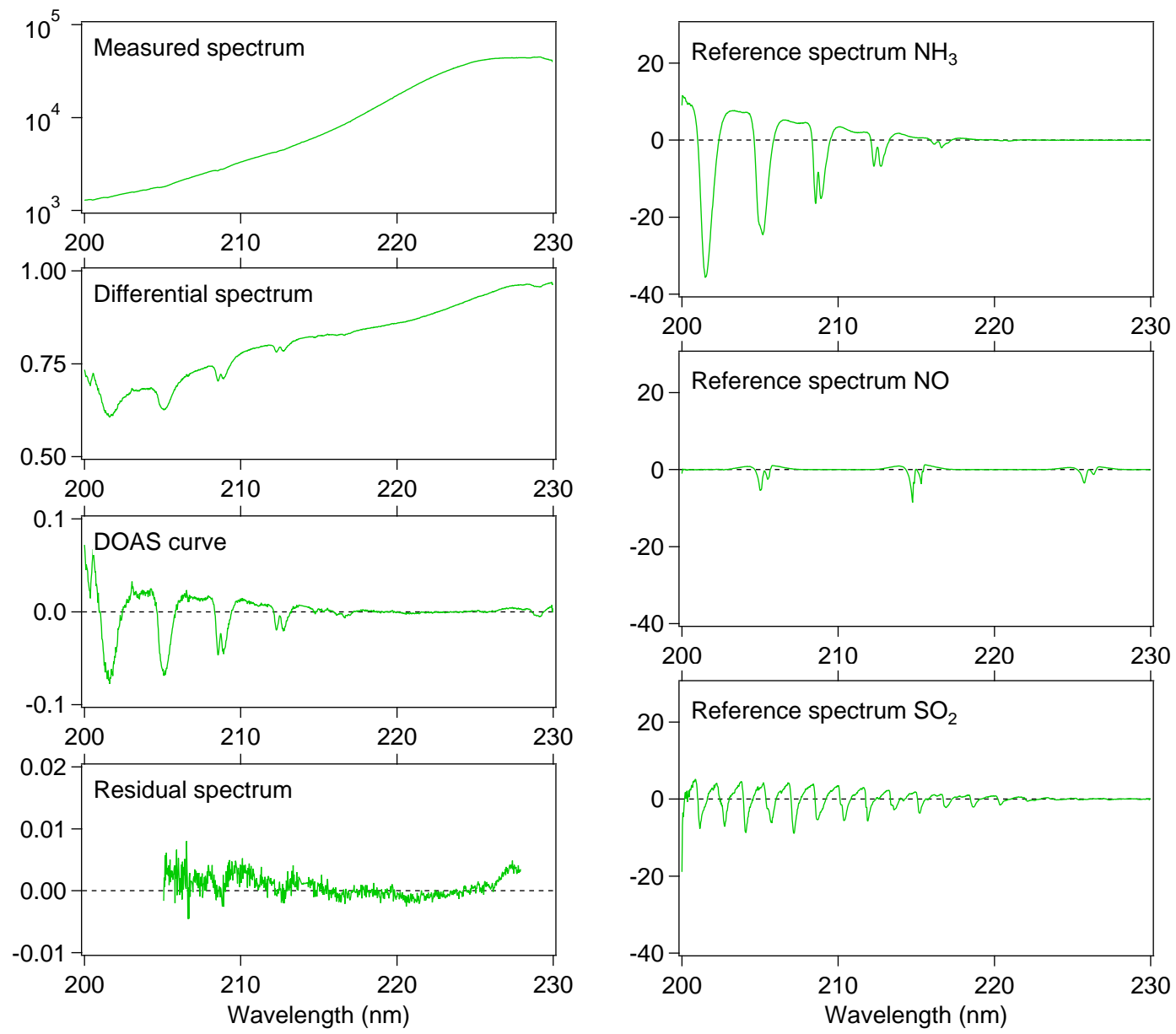

Fig. 8. Measurement analysis shown for a typical measurement. Left from top to bottom: measured spectrum (5-min average), differential spectrum $\left(I_{\lambda} / I_{0, \lambda}\right)$, DOAS curve $\left(\ln \left[\frac{I_{\lambda} / I_{0, \lambda}}{\left(I_{\lambda} / I_{0, \lambda}\right)_{\text {boxcar }}}\right]\right)$, and the residual spectrum. Right from top to bottom: $\mathrm{NH}_{3}$, $\mathrm{NO}$, and $\mathrm{SO}_{2}$ reference spectra used in the fitting procedure. Scales for the y-axes are arbitrary. Units for the reference spectra of $\mathrm{NH}_{3}, \mathrm{NO}$ and $\mathrm{SO}_{2}$ are the same. For these measured reference spectra, the concentrations were equivalent to ambient concentrations over a path length of $100 \mathrm{~m}$ of $200 \mu \mathrm{g} \mathrm{m}^{-3}$ for $\mathrm{NH}_{3}, 570 \mu \mathrm{g} \mathrm{m}^{-3}$ for $\mathrm{NO}$, and $50.6 \mu \mathrm{g} \mathrm{m}^{-3}$ for $\mathrm{SO}_{2}$. The residual spectrum is plotted in the same units as the DOAS curve. It is a tool that helps to identify potential flaws in the measurements, such as interference problems.

In addition, it may contain spectral features of other absorbing species if these are not accounted for in the analysis. Furthermore, the measured spectrum may contain digitizing errors because the spectral resolution of the spectrograph is limited $(0.0306 \mathrm{~nm}$ per pixel for the RIVM DOAS system and $0.056 \mathrm{~nm}$ per pixel for the RIVM MiniDOAS system), and because the light intensities are digitized by the CCD (16 bit per pixel for both DOAS systems). These digitizing errors will evolve throughout the analysis. The remaining residual spectrum determines the uncertainties in the calculated concentrations.

Apart from instrumental specifications, another important factor determining the uncertainty in the final concentration measurements is the total amount of light that is reflected onto the detector. This may, for example, depend on atmospheric conditions such as haze or fog which reduces the light intensity over the measurement path. To increase the precision in the concentration values, we average several measured spectra before analysis. For the RIVM DOAS concentration values, typically 200 spectra are collected and averaged in a 5-min interval, which for a light path of in total $100 \mathrm{~m}$ results in a typical standard deviation for $\mathrm{NH}_{3}$ of $0.15 \mu \mathrm{g} \mathrm{m}^{-3}$. The miniDOAS typically collects and averages more than 500 spectra in $1 \mathrm{~min}$, which results in a typical standard deviation of about $0.1 \mu \mathrm{g} \mathrm{m}^{-3}$ for a total light path of $100 \mathrm{~m}$.

\section{Laboratory tests}

The RIVM DOAS instrument has been tested in the laboratory for linear response to different concentrations of ammonia and for interference effects of nitrogen monoxide and 


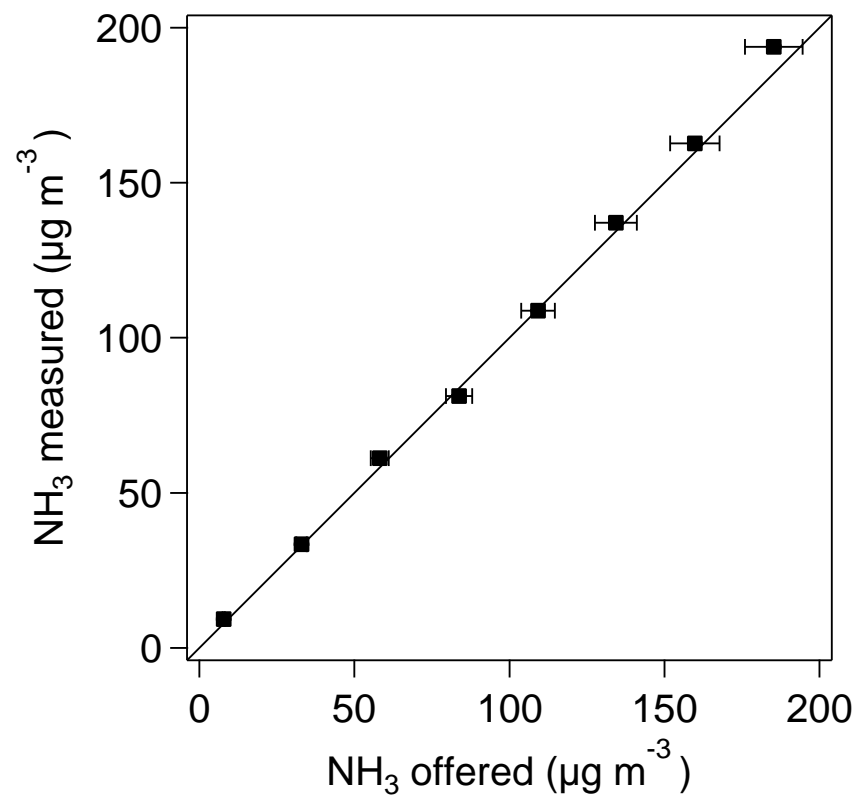

Fig. 9. Results of the linearity test for the RIVM DOAS instrument. Horizontal error bars indicate estimated errors of $5 \%$ in the $\mathrm{NH}_{3}$ concentrations offered. Vertical error bars indicate 1- $\sigma$ errors in the measured $\mathrm{NH}_{3}$ concentrations. If the error bars are not visible they are smaller than the symbol plotted.

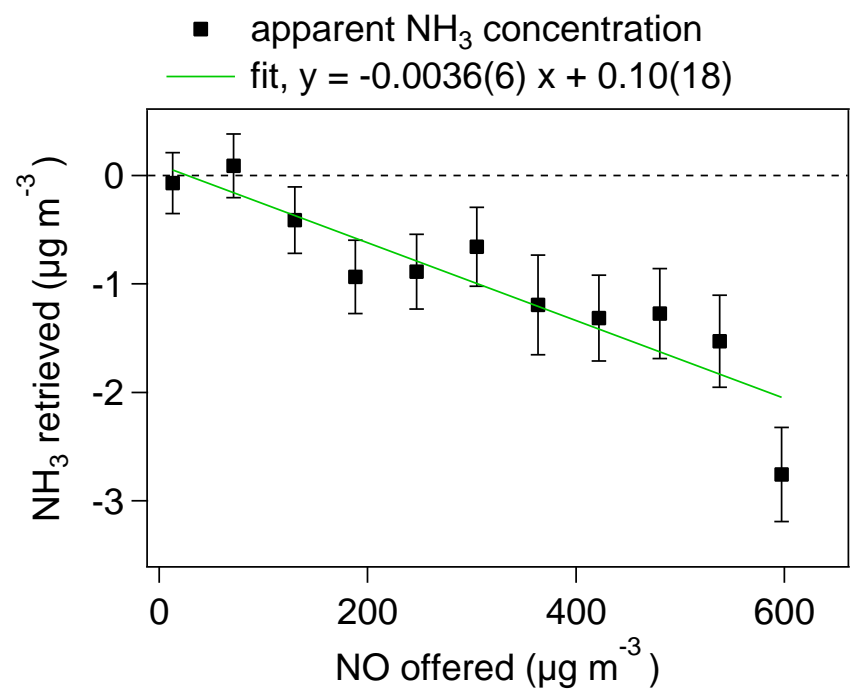

Fig. 10. Results of the NO interference test for the RIVM DOAS instrument.

sulfur dioxide concentrations. For the linearity test, eight $\mathrm{NH}_{3}$ concentrations between $15 \mathrm{ppm}$ and $500 \mathrm{ppm}$ were generated with a gas flow controller in a flow cell (Hellma, 225-QS Quartzglas Suprasil, $75 \mathrm{~mm}$; see Fig. 2). Pressure and temperature were measured during these experiments. These concentrations yield spectra equivalent to those seen from a $100 \mathrm{~m}$ path in the atmosphere, when the atmospheric

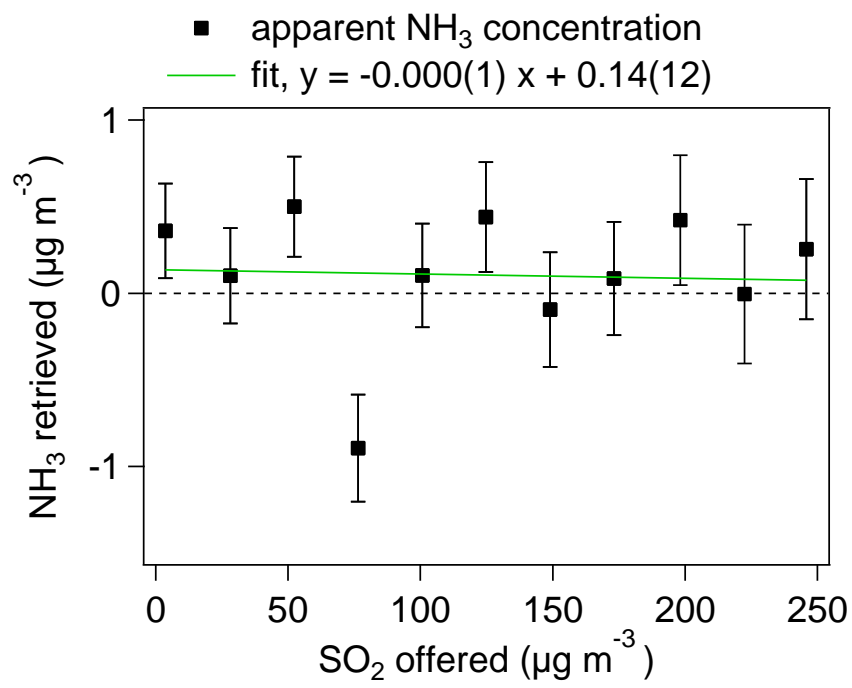

Fig. 11. Results of the $\mathrm{SO}_{2}$ interference test for the RIVM DOAS instrument.

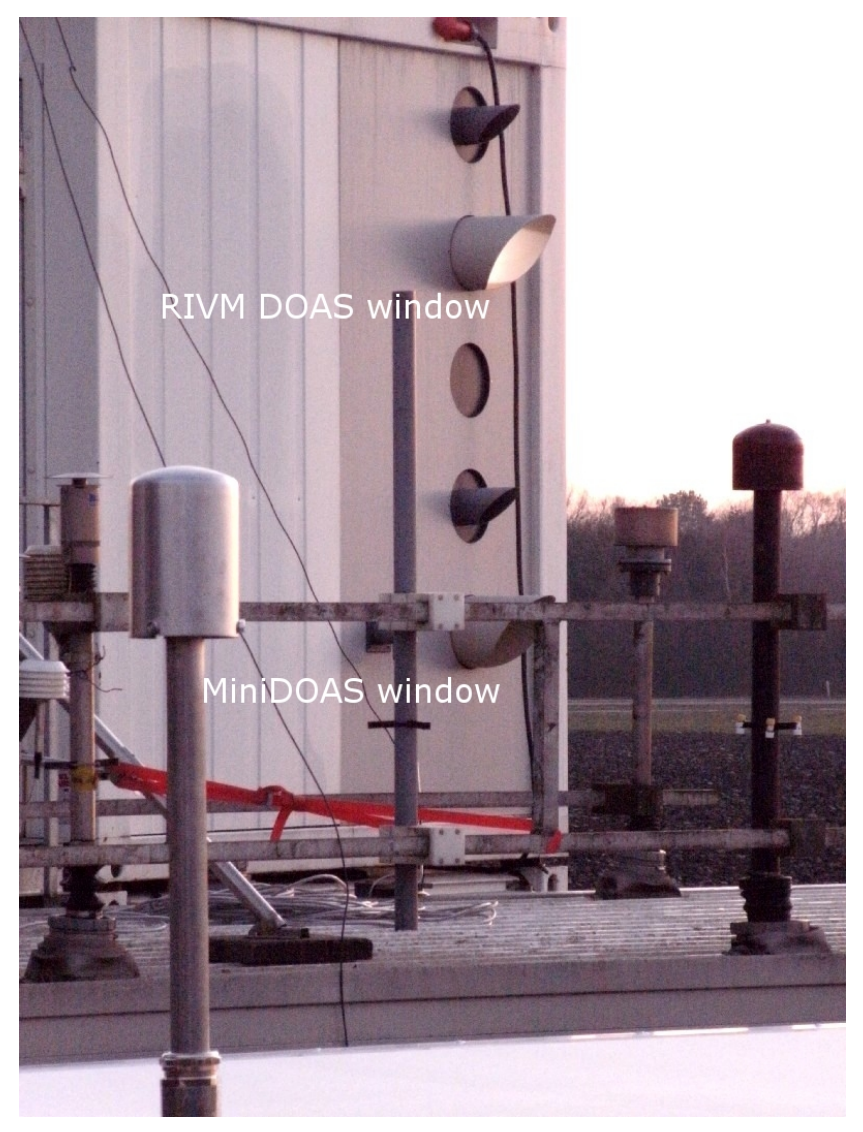

Fig. 12. Photo of measurement cabin with the two windows, of the RIVM DOAS (upper window, with light emerging) and the miniDOAS (lower window, partly hidden by a metal rail). The light of the lamps are directed directly over the inlet of the AMOR instrument inside the LML measurement cabin. 


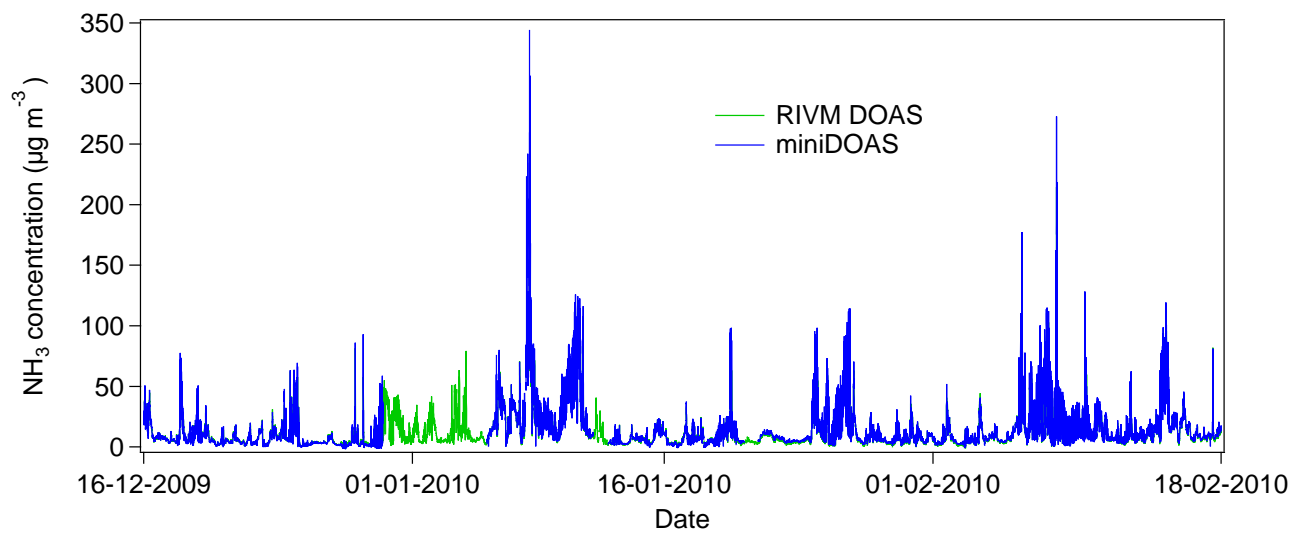

Fig. 13. RIVM DOAS (5-min values) and miniDOAS data (1-min values) obtained in the field in Vredepeel from 16 December 2009 to 18 February 2010.

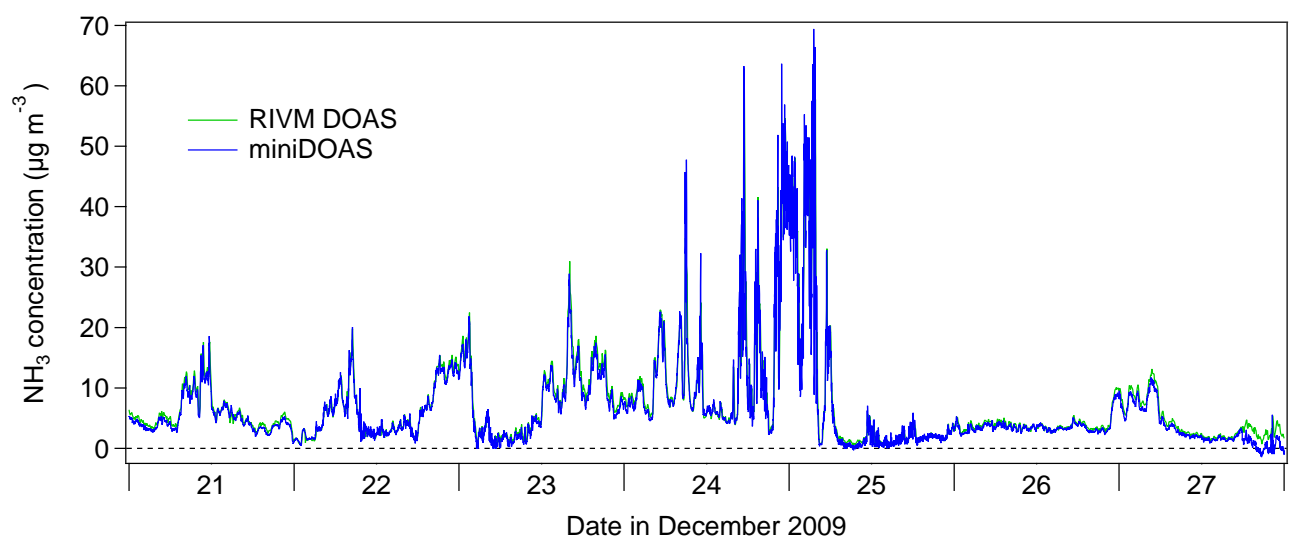

Fig. 14. Zoom in on the RIVM DOAS (5-min values) and miniDOAS data (1-min values) obtained in the field in Vredepeel from 21 to 28 December 2009.

concentrations are up to $200 \mu \mathrm{g} \mathrm{m}^{-3}$. For the conversion to equivalent atmospheric concentrations, a pressure of 1 atmosphere and a temperature of $20^{\circ} \mathrm{C}$ was assumed. The flow cell was positioned in the light path between the receiving mirror and the interference filter.

It is an important advantage of the DOAS systems that a linearity test or a span calibration procedure can be performed directly with ammonia gas cylinders in the ppm range, instead of the gas standards in the ppb range that are needed for the calibration of instruments using sample inlet lines. Providing gas standards in the ppb range is often only feasible under laboratory conditions.

For the interference tests, eleven concentrations of known amounts of nitrogen monoxide and sulfur dioxide were supplied in the flow cell, in a similar way as for the ammonia linearity test. For these concentrations we recorded the amount of interference to the retrieved $\mathrm{NH}_{3}$ concentrations.

\section{Test results}

The results of the linearity test for the RIVM DOAS is shown in Fig. 9 for equivalent atmospheric concentrations between 3 and $200 \mu \mathrm{g} \mathrm{m}^{-3}\left(1 \mathrm{ppb}=0.708 \mu \mathrm{g} \mathrm{m}^{-3}\right.$ for $p=1013 \mathrm{hPa}$ and $T=20^{\circ} \mathrm{C}$ ). The linearity of the RIVM DOAS response is excellent up to around $200 \mu \mathrm{g} \mathrm{m}^{-3}$. In the plot the combined uncertainties in the gas flow controller and the content of the gas cylinder have been estimated at $5 \%$. All data points are on the $y=x$ line within their error bars (see Fig. 9).

To test the potential interference by NO on the measured $\mathrm{NH}_{3}$ concentrations, we supplied $\mathrm{NO}$ in concentrations equivalent to atmospheric concentrations between 13 and $600 \mu \mathrm{g} \mathrm{m}^{-3}$, and recorded the apparent $\mathrm{NH}_{3}$ concentrations. The results are displayed in Fig. 10. A linear fit through the data points yields $y=-0.0036(6) x+0.10(18)$, with the standard deviation in the last digits indicated in parentheses. The annual average in the Netherlands for $\mathrm{NO}_{\mathrm{x}}\left(\mathrm{NO}+\mathrm{NO}_{2}\right)$ 


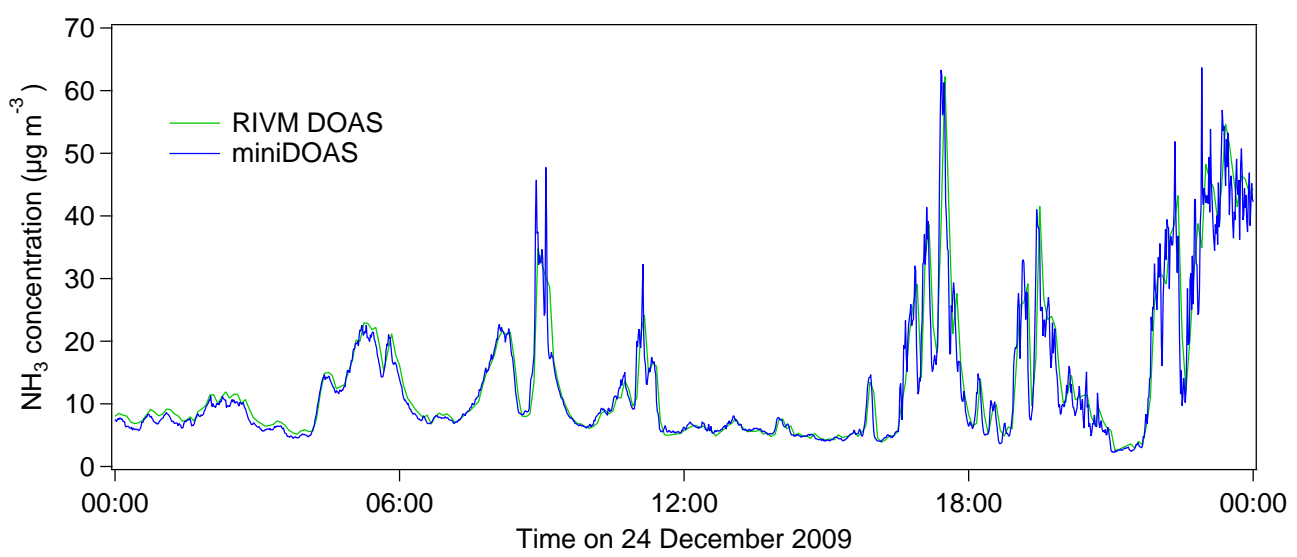

Fig. 15. A further zoom in on RIVM DOAS (5-min values) and miniDOAS data (1-min values) obtained in the field in Vredepeel on 24 December 2009.

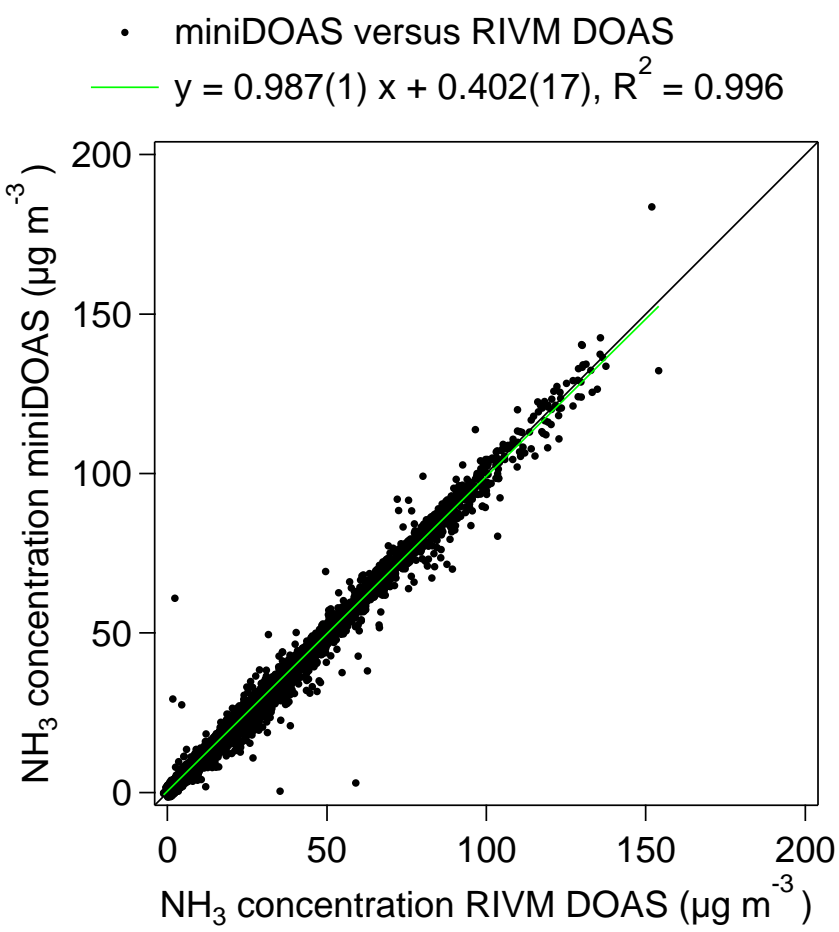

Fig. 16. Ammonia concentration values of the miniDOAS instrument versus RIVM DOAS concentration values. The miniDOAS 1-min concentrations have been converted to 5-min values to facilitate the comparison with the 5-min concentrations of the RIVM DOAS instrument. The number of data points used in this plot is 13903 . The results of both instruments show a high correlation $\left(R^{2}=0.996\right)$.

concentrations in 2007 was $25 \mathrm{\mu g} \mathrm{m}^{-3}$ (Beijk et al., 2007). If all this $\mathrm{NO}_{\mathrm{x}}$ would consist of $\mathrm{NO}$, it would yield an interference in the $\mathrm{NH}_{3}$ concentrations of $0.01(23) \mu \mathrm{g} \mathrm{m}^{-3}$. Locally, daily or hourly values for NO may be much higher, up to around $200 \mu \mathrm{g} \mathrm{m}^{-3}$. In these extreme cases the interference to the measured $\mathrm{NH}_{3}$ concentrations will only yield $-0.6(2) \mu \mathrm{g} \mathrm{m}^{-3}$.

To test the potential interference by $\mathrm{SO}_{2}$ to the measured $\mathrm{NH}_{3}$ concentrations, we supplied $\mathrm{SO}_{2}$ in concentrations equivalent to atmospheric concentrations between 3 and $250 \mu \mathrm{g} \mathrm{m}^{-3}$, and recorded the apparent $\mathrm{NH}_{3}$ concentrations. The results are displayed in Fig. 11. A linear fit through the data points yields $y=-0.000(1) x+0.14(12)$. $\mathrm{SO}_{2}$ concentrations in the Netherlands are usually low, the annual average is of the order of $2-3 \mu \mathrm{g} \mathrm{m}^{-3}$. Daily values rarely exceeded $9 \mu \mathrm{g} \mathrm{m}^{-3}$ in 2007 (Beijk et al., 2007). Therefore, in practice $\mathrm{SO}_{2}$ interference will not be significant for DOAS measurements.

\section{Field experiments}

The field measurements were performed on a LML measurement station in Vredepeel $\left(51^{\circ} 32^{\prime} 53^{\prime \prime} \mathrm{N}, 5^{\circ} 51^{\prime} 11^{\prime \prime} \mathrm{E}\right.$; see Fig. 12). Vredepeel is located in a region in the Netherlands with a annual average ammonia concentration of about $17 \mu \mathrm{g} \mathrm{m}^{-3}$. The RIVM DOAS and miniDOAS instruments were virtually continuously in operation for a period of about two months, from 16 December 2009 to 18 February 2010 (see Fig. 13). This period included episodes with steady, relatively low concentrations and episodes with rapidly-changing high concentrations (hourly values $>100 \mu \mathrm{g} \mathrm{m}^{-3}$ ). These high rapidly-changing concentrations are caused by livestock stabled in the vicinity to the northeast of the measurement station. The results for the period of more than two months shown in Fig. 13 illustrate that both DOAS instruments have a high uptime.

In general, the RIVM DOAS and miniDOAS measurement data agree excellently, as is illustrated in Fig. 14 which zooms in on a week of data obtained in December 2009, and Fig. 15 which zooms in even further to a day of data obtained on 24 December 2009 (arbitrarily chosen). Small differences 


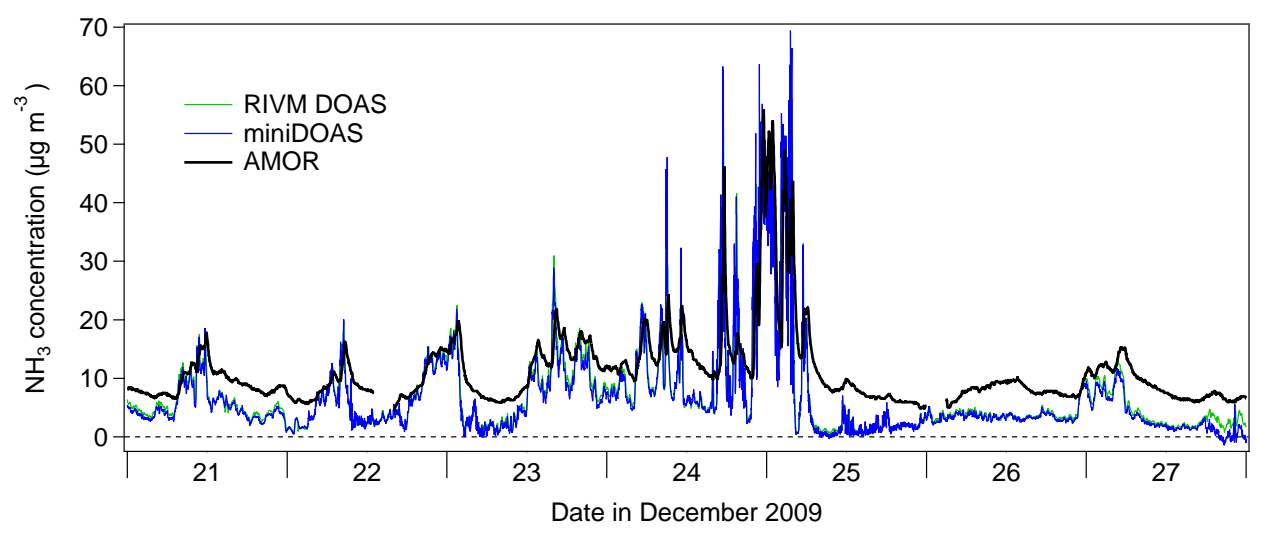

Fig. 17. RIVM DOAS (5-min values), miniDOAS (1-min values), and AMOR data (1-min values) obtained in the field in Vredepeel from 21 to 28 December 2009.

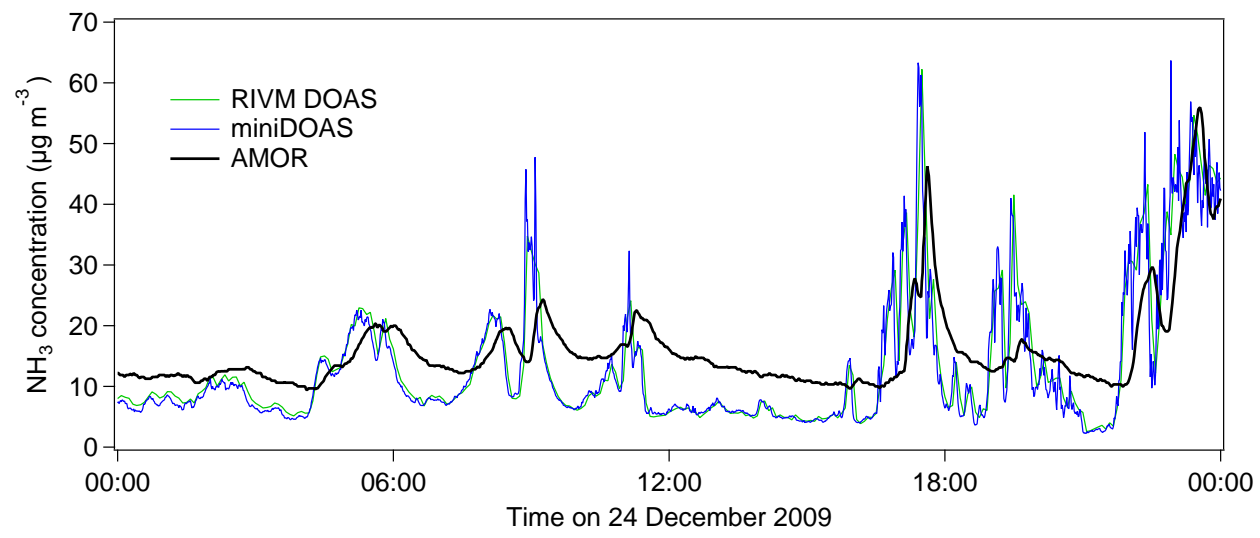

Fig. 18. RIVM DOAS (5-min values), miniDOAS (1-min values), and AMOR data (1-min values) obtained in the field in Vredepeel on 24 December 2009.

between the two instruments are mainly due to the difference in time resolution: the RIVM DOAS measures at 5-min intervals, the miniDOAS operates at 1-min intervals. Also, the difference in measurement height of about $1 \mathrm{~m}$ (see Fig. 12) may cause slight differences in the measured ammonia concentrations, due to ammonia deposition or emission effects.

The scatter plot (Fig. 16) further demonstrates the excellent correlation between the RIVM DOAS and the miniDOAS instruments. For this scatter plot, $13903 \mathrm{NH}_{3}$ values were used from data obtained between 18 December 2009 and 10 March 2010. The miniDOAS 1-min concentrations were converted to 5 -min values to facilitate the comparison with the 5-min concentrations of the RIVM DOAS instrument. A linear fit through the data points yields $y=0.987( \pm 0.001) x+0.402( \pm 0.017)$, and a high correlation, $R^{2}=0.996$.

\section{Comparison to AMOR data}

The Vredepeel station is part of the automatic atmospheric ammonia network (Beijk et al., 2007). Ammonia is continuously monitored with the AMOR instrument (Wyers et al., 1993). This is a wet-chemistry system with online analysis, also known as the AMANDA, developed by the Energy Research Foundation of the Netherlands (ECN) that has been adapted for use in a monitoring network (Buijsman et al., 1998). The presence of the AMOR at the Vredepeel station enabled us to compare the RIVM DOAS and miniDOAS measurements to the AMOR measurements. In Fig. 17 we show an example of the $\mathrm{NH}_{3}$ concentrations measured with the RIVM DOAS and the miniDOAS instruments from 21 to 28 December 2009, compared to concentrations measured with the AMOR instrument.

In Fig. 18 we zoom in further and we show measurements for 24 December 2009. In addition to the RIVM DOAS and miniDOAS data, AMOR data is plotted. Both Figs. 17 and 18 show that the AMOR curve follows the same trends as the (mini)DOAS curves, but it is delayed in following the peaks in the ammonia concentrations. This is a well known effect due to the turnover time of the liquids in the continuous flow denuder of the AMOR (e.g. von Bobrutzki et al., 2010). The delay also smooths the signal compared to the (mini)DOAS 


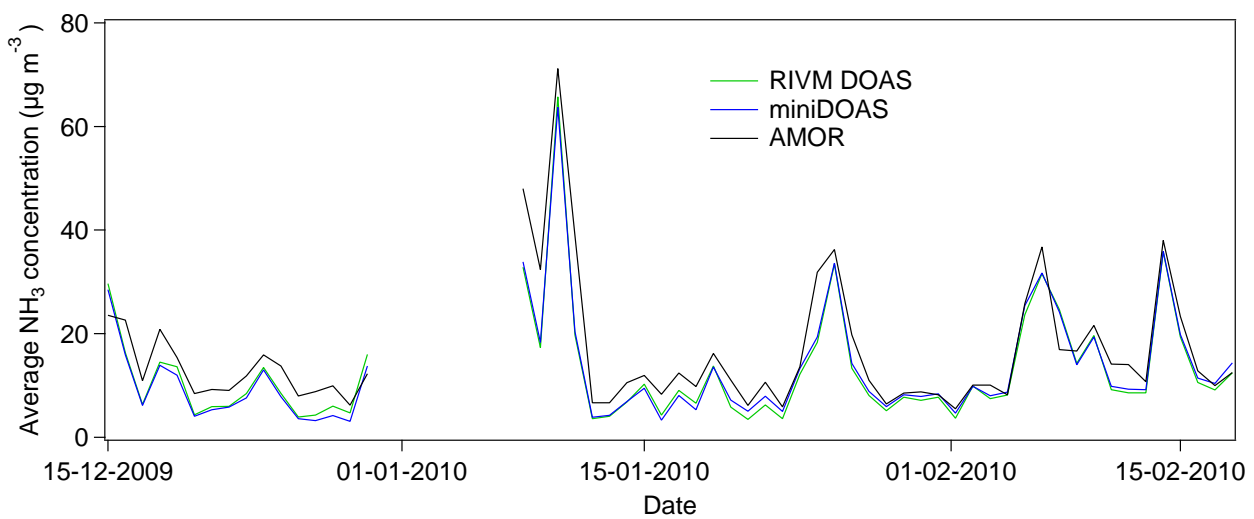

Fig. 19. Daily averaged values of RIVM DOAS, miniDOAS, and AMOR data obtained in the field in Vredepeel.

data. The AMOR seems to have difficulties to reach high peaks, and, in particular, it has problems to reach very low concentrations.

To investigate whether this behavior causes the AMOR to produce higher values on average or whether the differences between the AMOR and the (mini)DOAS are averaged out when longer periods are considered, we have plotted daily averages for the measured RIVM DOAS, miniDOAS, and AMOR concentrations in Fig. 19. The averages over the whole period plotted are $12.9 \mu \mathrm{g} \mathrm{m}^{-3}$ for the miniDOAS, $12.8 \mu \mathrm{g} \mathrm{m}^{-3}$ for the RIVM DOAS, and $16.3 \mu \mathrm{g} \mathrm{m}^{-3}$ for the AMOR measurements. Overall, the AMOR averages tend to be higher than the (mini)DOAS averages. This may be due to an additional memory effect caused by adsorption and desorption in the inlet lines of ammonia or ammonium aerosols dissociating after getting stuck. Possibly, this results in a (very slowly varying) background concentration of a few micrograms per cubic meter.

To be able to compare the data in more detail, we calculated a running mean from the miniDOAS data using (von Bobrutzki et al., 2010)

$c^{\prime}(t)=f c(t)+(1-f) c^{\prime}(t-1)$

where $c^{\prime}(t)$ is the delayed and smoothed concentration, $c(t)$ is the measured miniDOAS data and $f$ is a smoothing factor, which would be unity for an instrument equally fast as the miniDOAS. To simulate the AMOR data we use an e-folding time $\tau_{1 / \mathrm{e}}$ of $30 \mathrm{~min}$, where $\tau_{1 / \mathrm{e}}=1 / f$. The value of $30 \mathrm{~min}$ was determined using an eye-ball fit.

In Fig. 20 we plotted the minute values of the AMOR versus those of the miniDOAS (left panel) and the minute values of the AMOR versus the delayed and smoothed miniDOAS data (right panel). The linear fit, indicated in green, changed by including the delay from $y=0.95 x-3.07$ to $y=0.99 x-3.42$, the coefficient of determination, $R^{2}$, improved significantly from 0.65 to 0.90 . The fact that in the right scatter plot the data has become organized in apparent curves instead of scattered dots, probably indicates that a more sophisticated model would produce even better agreement. However, in this paper we do not aim at attaining the best possible fit to the AMOR data, we aim at making plausible that the differences between the AMOR and the (mini)DOAS data are mainly due to the slower response time of the AMOR instrument and a possible memory effect due to ammonia stuck to inlet lines.

Figure 21 illustrates the effect of the delay and smoothing on the miniDOAS data compared to the original miniDOAS data and the AMOR data. We added an offset concentration to the original miniDOAS data and to the delayed and smoothed miniDOAS data of $3.4 \mu \mathrm{g} \mathrm{m}^{-3}$, which is the difference between the miniDOAS and AMOR averages over the whole period. The AMOR data and the delayed and smoothed miniDOAS data are remarkably similar, indicating again that the differences between the (mini)DOAS results and the AMOR results are indeed mainly due to the slower response time of the AMOR instrument and a possible memory effect due to ammonia stuck to the inlet lines. Further small discrepancies between the AMOR data and the delayed and smoothed miniDOAS data may be attributed to the fact that the (mini)DOAS measures over a path of twice $50 \mathrm{~m}$ and the AMOR performs point measurements. For this reason, rapid concentration fluctuations in the air may not be seen by both instruments in the same way.

\section{Conclusions and outlook}

In this paper we described two Differential Optical Absorption Spectroscopy (DOAS) instruments built at RIVM, the RIVM DOAS and the miniDOAS. The instruments are suitable for the detection of $\mathrm{NH}_{3}$ concentrations in the atmosphere up to at least $200 \mu \mathrm{g} \mathrm{m}^{-3}$. The instruments have no inlet problems and no problems with interference by ammonium aerosols dissociating on tubes or filters because they measure over an open path. Laboratory tests showed that the RIVM DOAS instrument has a linear response over a concentration range of a few $\mu \mathrm{g} \mathrm{m}^{-3}$ up to around $200 \mu \mathrm{g} \mathrm{m}^{-3}$, 

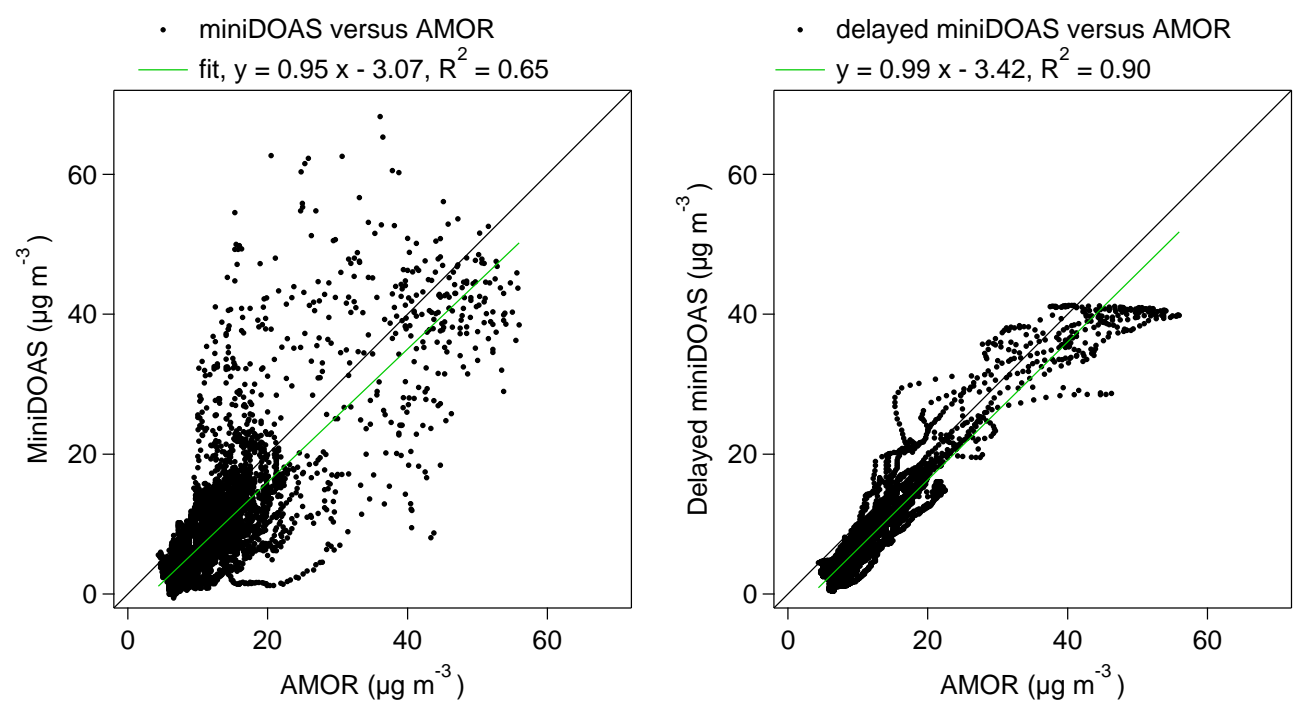

Fig. 20. Scatter plots of the minute values of the AMOR versus those of the miniDOAS (left panel) and of the minute values of the AMOR versus the delayed and smoothed miniDOAS data (right panel). Linear fits are indicated in green, the $y=x$ curve is plotted as a black line.

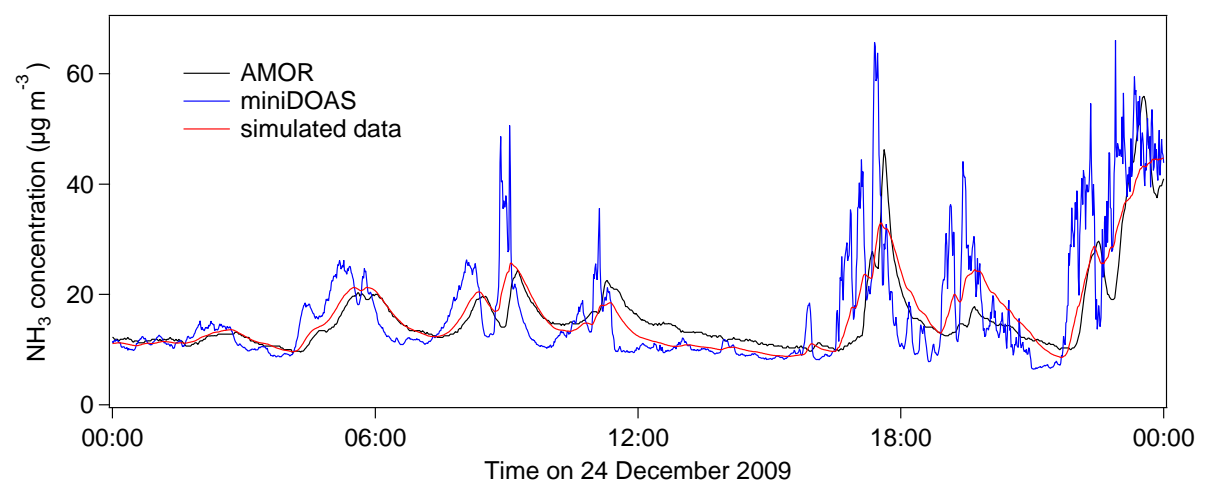

Fig. 21. Minute values of the miniDOAS, and the AMOR compared to delayed and smoothed miniDOAS data. Both the miniDOAS data and the delayed and smoothed miniDOAS data have been augmented with an offset of $3.4 \mu \mathrm{g} \mathrm{m}^{-3}$.

and that the potential interference by $\mathrm{NO}$ and $\mathrm{SO}_{2}$ at ambient levels is small to negligible. The results of a field comparison campaign of more than two months indicated that both instruments have a high uptime, and that the results of the RIVM DOAS and the miniDOAS agree well; the scatter plot shows a high correlation $\left(R^{2}=0.996\right)$. The agreement with the AMOR ammonia concentrations is less perfect, but still a very good agreement is obtained when a delay in the AMOR system due to the turnover time of its liquids is taken into account. Daily averages of all three systems agree reasonably well, although an offset of the AMOR values compared to the (mini)DOAS results exists. This offset is probably caused by three main reasons: (1) memory effects due to ammonia stuck to e.g. inlet tubes; (2) ammonium aerosols stuck to walls and inlet tubes, which eventually dissociate; and (3) a difference of sampled air between the AMOR, which performs a point measurement, and the (mini)DOAS, which per- forms a line measurement. Alternatively, the DOAS systems could underestimate the ammonia concentrations due to assumptions made during the calibration procedure. To determine zero and span values, we use measurements over a $1 \mathrm{~m}$ path assuming that the ambient ammonia contributions over this path may be neglected. However, if the ambient concentration would be high, e.g. $50 \mu \mathrm{g} \mathrm{m}^{-3}$, this would cause an offset in the zero concentration, resulting in an underestimation of the measured ammonia concentration by $0.5 \mu \mathrm{g} \mathrm{m}^{-3}$. For the span measurements using concentrations which are equivalent to ambient concentrations of $200 \mathrm{\mu g} \mathrm{m}^{-3}$, this additional $0.50 \mu \mathrm{g} \mathrm{m}^{-3}$ falls within the error of the measurements. In short, this potential underestimation of the DOAS systems could explain only a small part of the discrepancy of $3.4 \mu \mathrm{g} \mathrm{m}^{-3}$. 
The relatively high variability in the ammonia concentrations in Vredepeel may augment the differences between a fast reaction instrument like the (mini)DOAS and an instrument with a much slower response, such as the AMOR instrument. Therefore, we plan to perform further comparisons between the two types of instruments also on other locations with lower and more stable concentration levels to see if this influences the systematic differences between the instruments.

The performance of the RIVM DOAS instrument is excellent. One of the purposes of this paper was to demonstrate that the miniDOAS performs almost equally well, despite the fact that this instrument is about a factor of ten less costly, easier to handle, and much smaller in size. This opens up a great number of opportunities for the application of the miniDOAS. In the near future we will work on an implementation plan to introduce the miniDOAS into the Dutch National Air Quality Monitoring Network (LML) of the Netherlands. For this purpose we will study the possibilities of reducing the path length to the retroreflector from $50 \mathrm{~m}$ to around $10 \mathrm{~m}$, and of using a smaller UV lamp producing less heat. This would make it easier to install and maintain the instrument at more confined measurement locations. Also, some adaptations have to be made to have a fully automated instrument including remotely controlled data acquisition and error handling.

Another promising application for the miniDOAS is to use it for the measurement of ammonia fluxes, e.g. in nature areas. The relatively low cost of the instrument and the fact that it is low on maintenance brings within reach an ammonia flux monitoring network with high time resolution. To measure ammonia fluxes we need two miniDOAS instruments placed at different heights, combined with a sonic anemometer to measure wind speed (Wichink Kruit et al., 2010). In particular for this application of the miniDOAS, it will be highly desirable to design or procure a small, stable, weatherproof and temperature controlled housing that may be used in masts or on open frame towers.

Acknowledgements. We are indebted to Marc Kroonen of the Applied Plant Research site in Vredepeel for his help and hospitality during the ammonia measurement campaign. We greatly appreciate the constructive comments from Albrecht Neftel, Arjan Hensen, and an anonymous referee.

Edited by: P. Xie

\section{References}

Asman, W. A. H., Sutton, M. A., and Schjorring, J. K.: Ammonia: Emission, atmospheric transport and deposition, New Phytol., 139, 27-48, 1998.

Beijk, R., Mooibroek, D., and Hoogerbrugge, R.: Air quality in the Netherlands, 2003-2006, report 680704002, RIVM, 2007.

Buijsman, E., Aben, J. M. M., Van Elzakker, B. G., and Mennen, M. G.: An automatic atmospheric ammonia network in the
Netherlands set-up and results, Atmos. Environ., 32, 317-324, doi:10.1016/S1352-2310(97)00233-1, 1998.

Chen, F. Z., Judge, D. L., Wu, C. Y. R., and Caldwell, J.: Low and room temperature photoabsorption cross sections of $\mathrm{NH}_{3}$ in the UV region, Planet. Space Sci., 47, 261-266, 1999.

Cheung, A., Yoshino, K., Parkinson, W. H., Freeman, D. E., and Guberman, S. L.: Absorption cross section measurements of oxygen in the wavelength region 195-241 nm of the Herzberg continuum, Planet. Space Sci., 34, 1007-1021, doi:10.1016/0032-0633(86)90011-5, 1986.

Edner, H., Amer, R., Ragnarsson, P., Rudin, M., and Svanberg, S.: Atmospheric $\mathrm{NH}_{3}$ monitoring by long-path UV absorption spectroscopy, in: Society of Photo-Optical Instrumentation Engineers (SPIE) Conference Series, edited by: Nielsen, H. O., vol. 1269 of Presented at the Society of Photo-Optical Instrumentation Engineers (SPIE) Conference, 14-20, 1990.

Edner, H., Ragnarson, P., Spannare, S., and Svanberg, S.: Differential optical absorption spectroscopy (DOAS) system for urban atmospheric pollution monitoring, Appl. Opt., 32, 327-333, 1993.

Jenouvrier, A., Coquart, B., and Merienne, M. F.: The $\mathrm{NO}_{2}$ absorption spectrum, III: The $200-300 \mathrm{~nm}$ region at ambient temperature, J. Atmos. Chem., 25, 21-32, 1996.

Keller-Rudek, H. and Moortgat, G. K.: MPI-Mainz-UV-VIS Spectral Atlas of Gaseous Molecules, available at: www.atmosphere. mpg.de/spectral-atlas-mainz, last access: July 2011, 2010.

Kendall, M. G. and Stuart, A.: The advanced theory of statistics, vol. 2, Hafner, Oxford, England, 1967.

Manatt, S. L. and Lane, A. L.: A compilation of the absorption cross-sections of $\mathrm{SO}_{2}$ from 106 to $403 \mathrm{~nm}$, J. Quant. Spectrosc. Ra., 50, 267-276, doi:10.1016/0022-4073(93)90077-U, 1993.

Molina, L. T. and Molina, M. J.: Absolute absorption cross sections of ozone in the 185- to 350-nm wavelength range, J. Geophys. Res., 91, 14501-14508, doi:10.1029/JD091iD13p14501, 1986.

Mount, G. H., Rumburg, B., Havig, J., Lamb, B., Westberg, H., Yonge, D., Johnson, K., and Kincaid, R.: Measurement of atmospheric ammonia at a dairy using differential optical absorption spectroscopy in the mid-ultraviolet, Atmos. Environ., 36, 17991810, 2002.

Selwyn, G., Podolske, J., and Johnston, H. S.: Nitrous oxide ultraviolet absorption spectrum at stratospheric temperatures, Geophys. Res. Lett., 4, 427-430, doi:10.1029/GL004i010p00427, 1977.

Shemansky, D. E.: $\mathrm{CO}_{2}$ Extinction Coefficient 1700-3000 A, J. Chem. Phys., 56, 1582-1587, doi:10.1063/1.1677408, 1972.

Thijsse, T. R., Duyzer, J. H., Verhagen, H. L. M., Wyers, G. P., Wayers, A., and Möls, J. J.: Measurement of ambient ammonia with diffusion tube samplers, Atmos. Environ., 32, 333-337, 1998.

Thompson, B. A., Harteck, P., and Reeves Jr., R. R.: Ultraviolet Absorption Coefficients of $\mathrm{CO}_{2}, \mathrm{CO}, \mathrm{O}_{2} \mathrm{H}_{2} \mathrm{O}, \mathrm{N}_{2} \mathrm{O}, \mathrm{NH}_{3}, \mathrm{NO}$, $\mathrm{SO}_{2}$, and $\mathrm{CH}_{4}$ between 1850 and $4000 \AA$, J. Geophys. Res., 68, 6431-6436, 1963.

Van Putten, E. M., Mennen, M. G., Regts, T., and Uiterwijk, J. W.: Performance study of four automatic ammonia monitors under controlled conditions, report 723101004, RIVM, 1994.

von Bobrutzki, K., Braban, C. F., Famulari, D., Jones, S. K., Blackall, T., Smith, T. E. L., Blom, M., Coe, H., Gallagher, M., Ghalaieny, M., McGillen, M. R., Percival, C. J., Whitehead, J. D., Ellis, R., Murphy, J., Mohacsi, A., Pogany, A., Junninen, H., Rantanen, S., Sutton, M. A., and Nemitz, E.: Field inter-comparison of eleven atmospheric ammonia measurement techniques, Atmos. 
Meas. Tech., 3, 91-112, doi:10.5194/amt-3-91-2010, 2010.

Wichink Kruit, R. J., Van Pul, W. A. J., Otjes, R. P., Hofschreuder, P., Jacobs, A. F. G., and Holtslag, A. A. M.: Ammonia fluxes and derived canopy compensation points over non-fertilized agricultural grassland in The Netherlands using the new gradient ammonia-high accuracy-monitor (GRAHAM), Atmos. Environ., 41, 1275-1287, 2007.

Wichink Kruit, R. J., Volten, H., Haaima, M., Swart, D. P. J., Van Zanten, M. C., and Van Pul, W. A. J.: Ammonia exchange measurements over a corn field in Lelystad, the Netherlands in 2009, Report 680180002/2010, RIVM, 2010.
Wyers, G. P., Otjes, R. P., and Slanina, J.: A continuous-flow denuder for the measurement of ambient concentrations and surface-exchange fluxes of ammonia, Atmos. Environ., 27A, 2085-2090, 1993.

Yoshino, K., Esmond, J. R., Cheung, A., Freeman, D. E., and Parkinson, W. H.: High resolution absorption cross sections in the transmission window region of the Schumann-Runge bands and Herzberg continuum of $\mathrm{O}_{2}$, Planet. Space Sci., 40, 185-192, doi:10.1016/0032-0633(92)90056-T, 1992. 